\title{
Mel e açúcar mascavo na cicatrização de feridas
}

\author{
Honey and brown sugar in wounds healing
}

\author{
Ivan Felismino Charas dos Santos ${ }^{\mathrm{I}, \mathrm{III}}$ Sara Luisa Sousa Grosso ${ }^{\mathrm{II}}$ Otilia Bata Bambo $^{\mathrm{III}}$ \\ André Paulo Nhambirre ${ }^{\mathrm{II}}$ José Manuel Mota Cardoso $^{\mathrm{III}}$ Elizabeth Moreira dos Santos Schmidt $^{\mathrm{IV}}$ \\ Renata Bezerra Marujo ${ }^{\mathrm{V}}$
}

\section{RESUMO}

\begin{abstract}
O estudo teve como objetivo comparar a eficácia do mel e do açúcar mascavo na cicatrização de feridas induzidas cirurgicamente na pele de cobaias, para avaliar o tempo de cicatrização, as variações macroscópicas e microscópicas do tecido cicatricial, a contração das feridas e o grau de contaminação. Quinze cobaias da raça Abissínia, machos inteiros, de seis meses de idade e pesando entre 500 a 850 gramas, foram divididas em três grupos com cinco animais cada, nos quais foram induzidas, cirurgicamente, três feridas em cada animal com dimensão de $1,5 \mathrm{~cm}^{2}$ e distância entre elas de 1,5cm, na região dorsal. A ferida $F 1$ foi tratada diariamente com mel, a ferida F2 com solução salina 0,9\% (controle) e a ferida F3 com o açúcar mascavo. A eutanásia foi realizada no Grupo 1 ao sétimo dia após a cirurgia, no Grupo 2 ao décimo quarto dia e no Grupo 3 no vigésimo primeiro dia após a cirurgia, sendo as biópsias encaminhadas para avaliação histopatológica. Foram também realizados swabs das feridas em todos os grupos no terceiro e sétimo dias após a cirurgia e as amostras enviadas para a cultura e isolamento bacteriano. Concluiu-se que as feridas tratadas com o mel cicatrizaram mais rápido em relação às tratadas com o açúcar mascavo, demonstrando a maior propriedade cicatrizante do mel em relação ao açúcar mascavo.
\end{abstract}

Palavras-chave: evolução cicatricial, mel, açúcar mascavo, lesões cutâneas, pele.

\section{ABSTRACT}

The study aimed to compare the effectiveness of honey and brown sugar in wounds healing induced in the skin of guinea pigs, to evaluate the healing time, microscopic and macroscopic healing variations, wound contraction and contamination degree. Fifteen guinea pigs, Abyssinia breed, males, six months of age and weighing between 500 to 850 grams, were divided in three groups with five animals each. Three wounds were promoted in each animal, surgical, with $1.5 \mathrm{~cm}^{2}$ and $1.5 \mathrm{~cm}$ between them, in the dorsal region. The F1 was treated, daily, with honey, F2 with saline solution 0,9\% (control) and F3 with brown sugar. Euthanasia was performed in Group 1 on the seventh day after the surgery, Group 2 on the fourteenth day and the Group 3 on the twenty-first day after the surgery and the biopsies sent to histopathological evaluation. Wounds swabs were made in all groups on the third and seventh days after the surgery and the samples sent for culture and bacterial isolation. The wounds treated with honey healed faster than treated with brown sugar.

Key words: healing progression, honey, brown sugar, cutaneous lesions, skin.

\section{INTRODUÇÃO}

Existe, atualmente, em todo mundo, uma grande tendência para o aproveitamento de recursos naturais na medicina, por apresentarem vantagens econômicas, serem eficientes e apresentarem poucos efeitos colaterais. Dentre as substâncias naturais mais utilizadas para cicatrização de feridas cutâneas,

'Programa de Pós-graduação em Medicina Veterinária, Faculdade de Medicina Veterinária e Zootecnia (FMVZ), Universidade Estadual Paulista Júlio de Mesquita Filho (UNESP), Distrito de Rubião Jr, s/n, 18618-970, Botucatu, SP, Brasil. E-mail: ivansantos7@ hotmail.com. Autor para correspondência.

"Curso de Medicina Veterinária, Faculdade de Veterinária (FV), Universidade Eduardo Mondlane (UEM), Maputo, Moçambique. IIIDepartamento de Cirurgia, Faculdade de Veterinária (FV), Universidade Eduardo Mondlane (UEM), Maputo, Moçambique.

${ }^{\text {IV }}$ Departamento de Clínica Veterinária, FMVZ, UNESP, Botucatu, SP, Brasil.

${ }^{\vee}$ Médica Veterinária Autônoma, Ribeirão Preto, SP, Brasil. 
destacam-se o mel e o açúcar mascavo (OLIVEIRA et al., 2000). Desde 2000 A.C., reporta-se o uso do mel no tratamento de feridas. Dentre as várias propriedades do mel, as mais relevantes no tratamento de feridas são o debridamento, devido à capacidade de formar o peróxido de hidrogênio (MOLAN, 2001; HENRIQUES, 2004; MORRIS, 2008), a formação do tecido de granulação e epitelização, pela formação de peróxido de hidrogênio e pelo $\mathrm{pH}$ ácido que promove a acidificação do meio, promovendo por sua vez a cicatrização ao estimular a libertação de oxigênio na ferida (MOLAN, 2001), o efeito anti-inflamatório associado ao efeito antioxidante (YOUNG, 2005) e o efeito antibacteriano associado à pouca presença de água livre (HADDAD et al., 2000; HENRIQUES, 2004; MORRIS, 2008).

O uso do açúcar mascavo no tratamento de feridas foi, pela primeira vez, reportado em 1679. As suas propriedades na cicatrização são similares às do mel, incluindo o debridamento dos tecidos necróticos e desvitalizados através da degradação da fibrina e pela estimulação dos macrófagos (HADDAD et al., 2000). A desvantagem do seu uso inclui a desidratação das células epiteliais, macrófagos e fibroblastos nas margens da ferida, inibindo a divisão e a migração celular $\mathrm{e}$, consequentemente, retardando a cicatrização da ferida (HADDAD et al., 2000).

Devido à ausência de relatos na literatura sobre a comparação do mel e do açúcar mascavo no tratamento de feridas na pele, a presente pesquisa objetiva comparar a eficácia de ambos como agentes cicatrizantes em feridas cutâneas, induzidas cirurgicamente em cobaias, para avaliar o tempo de cicatrização, as variações macroscópicas e microscópicas do tecido cicatricial e o grau de contaminação.

\section{MATERIAL E MÉTODOS}

Após aprovação pela CEUA/ FMVZUNESP-Botucatu e liberação com número de protocolo 58/2012, foram utilizadas 15 cobaias da raça Abissínia, machos inteiros, hígidos, com seis meses de idade e com um peso variado de 500 a 850 gramas. Os animais foram adquiridos em biotério com ambiente controlado de temperatura de $22^{\circ} \mathrm{C}$ e umidade de $45 \%$, com ciclo de 12 horas luz e 12 horas escuro. A pesquisa foi realizada em lugar com as condições similares ao biotério de origem. Foram utilizados no estudo, $0,5 \mathrm{~mL}$ do mel e 0,2 gramas do açúcar mascavo em cada ferida.

As cobaias foram divididas, aleatoriamente, em três grupos de cinco animais. Foi realizado um exame físico prévio, aferindo a temperatura retal e a mensuração do peso vivo. Em seguida, foi realizada uma tricotomia da região dorsal, desde a região torácica até a região sacral, estendendo-se para região costal esquerda e direita. A pré-medicação anestésica foi realizada com carprofen ${ }^{\mathrm{a}}$ ( $4 \mathrm{mg} \mathrm{kg}^{-1}$, via subcutânea) e morfina $^{\mathrm{b}}\left(2 \mathrm{mg} \mathrm{kg}^{-1}\right.$, via subcutânea). A indução anestésica foi com uma combinação de cetamina ${ }^{c}(70 \mathrm{mg}$ $\left.\mathrm{kg}^{-1}\right)$ e medetomidina ${ }^{\mathrm{d}}\left(0,5 \mathrm{mg} \mathrm{kg}^{-1}\right)$ por via intraperitoneal. A manutenção anestésica foi realizada com isoflurano ${ }^{\mathrm{e}}(2 \%)$, utilizando máscara inalatória.

Em todos os grupos, foram realizadas marcações na região dorsal da pele, de $1,5 \mathrm{~cm}^{2} \mathrm{e} 1,5 \mathrm{~cm}$ de distância entre elas. Foram induzidas, cirurgicamente, três feridas na região dorsal, no sentido craniocaudal, com designação de F1, F2 e F3, respectivamente, e uma profundidade até o tecido subcutâneo. Após a cirurgia, utilizou-se $o$ atipamezole ${ }^{f}\left(35 \mathrm{mg} \mathrm{kg}^{-1}\right.$, via intramuscular), para reverter o efeito sedativo da medetomidina. Foi usado o carprofen durante 3 dias para o controle da dor pós-operatória. Os tratamentos foram realizados diariamente e consistiam na troca dos curativos, avaliação macroscópica das feridas, mensuração da temperatura retal e pesagem dos animais. A avaliação macroscópica das feridas foi de acordo com o tamanho e contração das feridas, presença de hemorragia, crosta, edema e pus, e formação do tecido de granulação. $O$ grau de contração da ferida foi avaliado mediante a seguinte fórmula, desenvolvida por AGREN et al. (1997):

$$
\% \text { de contração no dia da medida }=\frac{(\text { Área inicial }- \text { Área do dia da medida) }}{\text { Área inizial }} \times 100
$$

A primeira ferida (F1) foi tratada com mel, na segunda ferida (F2) foi aplicada solução salina $0,9 \%$ (controle) e a terceira ferida (F3) foi tratada com açúcar mascavo. Antecedendo o tratamento diário, as feridas foram limpas com solução salina a $0,9 \%$ e as crostas removidas. Tanto o mel como o açúcar mascavo foram aplicados de modo a cobrir por completo as feridas e cobertas com uma gaze. A eutanásia foi realizada com pentobarbital sódico ${ }^{\mathrm{g}}$ (100 $\mathrm{mg} \mathrm{kg}^{-1}$, via intraperitoneal) ao sétimo dia pós-cirurgia para o Grupo I, ao décimo quarto dia para o Grupo II e ao vigésimo primeiro dia pós-cirurgia para o Grupo III. As amostras foram colocadas em frascos estéreis contendo formol a $10 \%$ e encaminhados para a histopatologia, onde foram processadas e coradas com solução de hematoxilina e eosina para avaliação das camadas dérmicas, presença de células de reação inflamatória e diferenciação celular.

Durante o estudo, não foi aplicado nenhum antibiótico. Foram obtidos swabs estéreis das feridas em todos os grupos, no terceiro e sétimo dias póscirurgia e enviadas para cultura e isolamento bacteriano. Os resultados foram analisados e comparados estatisticamente usando o programa SPSS $^{\circledR}$, com 
análise de variância (ANOVA), seguido do Teste de Tukey com 5\% de significância para comparação das médias $(\mathrm{P}<0,05)$.

\section{RESULTADOS E DISCUSSÃO}

A temperatura retal manteve-se dentro dos valores fisiológicos normais da espécie, variando entre $37^{\circ} \mathrm{C}$ a $38^{\circ} \mathrm{C}$. Em relação ao peso, observou-se uma variação durante a pesquisa, com uma diminuição nos primeiros quatro dias após a cirurgia, registrando-se uma elevação a partir do quinto dia após a cirurgia e normalização do peso até o final da pesquisa. Essa variação poderá ter sido pelo stress do animal frente às cirurgias, segundo PANTHONG et al. (2007). A diminuição de peso, observada nos primeiros dias da pesquisa, também pode estar associada com o processo inflamatório. Durante esse processo, ocorre a produção de citoquinas inflamatórias, interleucina 1, interleucina 6 e factor de necrose tumoral, e consequentemente as proteínas de fase aguda, que agem como mediadores da inflamação e da imunidade. Níveis elevados do factor de necrose tumoral podem causar a perda de peso, devido à estimulação da elevação da leptina (PASCHOALINI et al., 2005). Níveis elevados dessa proteína induzem o organismo ao gasto energético e a uma diminuição no consumo de alimentos, consequentemente perda de peso e o retorno do peso pode indicar o fim do processo inflamatório (PASCHOALINI et al., 2005).

Em todos os grupos, as feridas não apresentaram sinais macroscópicos de infecção durante todo o estudo. A partir do terceiro dia de tratamento, houve formação de uma crosta nas feridas em todos os grupos avaliados. No sétimo dia de tratamento, observou-se uma menor área das feridas tratadas com o mel e presença de tecido de granulação, quando comparadas com o açúcar mascavo, e as feridas tratadas com o açúcar mascavo apresentaram caraterísticas úmida e brilhante. No $14^{\circ}$ dia de tratamento, registrou-se uma redução do tamanho das feridas em todos os grupos. No $21^{\circ}$ dia de tratamento, as feridas de todos os grupos estavam totalmente cicatrizadas, no entanto, verificou-se a presença de uma crosta em uma das feridas tratadas com o açúcar mascavo e em todas do grupo controle.

O tempo médio de oclusão nas feridas tratadas com o mel foi de 16 dias, no grupo tratado com o açúcar mascavo, e com a solução salina $0,9 \%$ foi de 19 dias, não havendo diferença entre o grupo tratado com o açúcar mascavo e o grupo controle. Nas feridas tratadas com o mel, observou-se uma ligeira diminuição do diâmetro até ao quarto dia de tratamento, seguido de uma diminuição mais acentuada e mantendo-se até ao $16^{\circ}$ dia de tratamento. As feridas tratadas com o açúcar mascavo, durante os primeiros quatro dias de tratamento, apresentaram uma ligeira diminuição do seu diâmetro inicial e, a partir do sétimo dia, registrou-se uma diminuição acentuada que se manteve até ao $19^{\circ}$ dia de tratamento. Em relação às feridas do grupo controle, observou-se uma tendência similar às feridas tratadas com o mel, diferenciando apenas na diminuição mais acentuda até ao $19^{\circ}$ dia de tratamento.

Ao sétimo dia de tratamento, o aumento do diâmetro das feridas tratadas com o açúcar mascavo foi acentuado, ao contrário do verificado nas feridas tratadas com o mel e com a solução salina $0,9 \%$, em que se registrou uma diminuição de suas áreas. Essa diminuição poderá ter ocorrido devido à lavagem das feridas com a solução salina no momento da limpeza diária. Por outro lado, a limpeza evita o traumatismo direto da ferida, porque hidrata e favorece a sua cicatrização. SANTOS \& NEVES (1995) e MATHEWS \& BINNINGTON (2002) não recomendam a limpeza por meio de irrigação com solução salina, por considerarem que o procedimento pode alterar a capacidade de absorção do açúcar, levando, consequentemente, à diminuição da sua ação sobre a ferida, mas recomendam a lavagem com água corrente. Nos dois primeiros dias após a indução das feridas, a quantidade de exsudado foi maior em todos os grupos, desaparecendo após o $3^{\circ}$ dia de tratamento. O exsudado diminui a capacidade cicatrizante do açúcar mascavo devido a sua rápida diluição (MATHEWS \& BINNINGTON, 2002), daí o maior diâmetro nas feridas tratadas com o açúcar mascavo no mesmo período.

No presente estudo, a troca do curativo foi realizada a cada 24 horas. De acordo com a literatura (SANTOS \& NEVES, 1995; MATHEWS \& BINNINGTON, 2002), as trocas do curativo devem ser realizadas com intervalos de $6,8,12$ ou 24 horas, respectivamente. No entanto, CAVAZANA et al. (2009) afirmaram que a troca pode ser realizada a cada $24 \mathrm{~h}$ sem interferência para a cicatrização. A natureza viscosa do mel permitiu que o tempo de contacto entre a superfície da ferida e o mel fosse maior, ao contrário do grupo das feridas tratadas com o açúcar mascavo, que necessitou de um penso, de modo a promover maior tempo de contacto.

Durante todo o perído do estudo, observouse que ocorreu uma variação da área das feridas nos três grupos, quer dentro de cada grupo e de um grupo com relação ao outro. A diferença não foi estatisticamente significativa $(\mathrm{P}>0,05)$ e a variação pode ter sido devido à retração centrípeta pela tensão elástica da pele circunjacente, pela perda de aderência à fáscia 
profunda e devido à mobilidade da pele das cobaias, de acordo com OLIVEIRA et al. (2000).

Ao sétimo dia de tratamento, as feridas tratadas com o mel apresentaram contração em $91,7 \%$ dos animais (11/12), tendo ocorrido aumento da área da ferida em 8,3\% dos animais (1/12). A porcentagem de contração das feridas foi de $33,96 \%$. As feridas tratadas com o açúcar mascavo aumentaram de diâmetro em $66,7 \%$ dos animais (8/12), tendo-se registrado, nestes, um aumento da área da ferida de $22 \%$ em relação ao tamanho inicial, sendo a porcentagem de contração da ferida negativa de $6,75 \%$. No grupo controle, observou-se o aumento da área da lesão em 16,67\% dos animais (2/12), tendo-se registado contracção da área da lesão em 83,3\% (10/ 12). Ao $14^{\circ}$ dia após a cirurgia, observou-se menor diâmetro das feridas tratadas com o mel, tendo uma das feridas finalizado o processo cicatricial e a porcentagem de contração foi de $88,9 \%$. Nas feridas tratadas com o açúcar mascavo, foi registrada uma porcentagem de contração de $70,04 \%$. Nas feridas tratadas com a solução salina $0,9 \%$, observou-se uma porcentagem de contraç̧ão de $79,06 \%$.

Ao sétimo, $14^{\circ}$ e $21^{\circ}$ dias de tratamento, as feridas tratadas com o mel apresentaram maior área contração em relação às feridas tratadas com o açúcar mascavo e com a solução salina $0,9 \%$. Esses resultados demonstram o maior efeito anti-inflamatório e de estimulação da formação do tecido de granulação que o mel possui em relação o açúcar mascavo (MATHEWS \& BINNINGTON, 2002, HENRIQUES, 2004, YOUNG, 2005; MORRIS, 2008). A presença de neovascularização nas feridas tratadas com o mel está de acordo com o citado por MATHEWS \& BINNINGTON (2002), permitindo a nutrição e oxigenação da área lesionada e consequentemente cicatrização mais rápida. Contrariamente, o açúcar mascavo demonstrou ter capacidade de contração menor em relação ao grupo controle.

O primeiro $s w a b$ foi realizado no terceiro dia de tratamento, contrariamente ao citado pela literatura (RAHAL et al., 2001), que se refere à realização dos swabs logo após a cirurgia, porque o objetivo era a observação da ação antibacteriana do mel e do açúcar mascavo após 72 horas de ação. O segundo foi realizado ao sétimo dia de tratamento, com a finalidade de comparar os resultados encontrados no primeiro swab. No terceiro dia de tratamento, observou-se a presença de Pseudomonas aeruginosa e Staphyllococcus aureus nos grupos das feridas tratadas com o açúcar mascavo e no grupo controle. Por outro lado, no grupo das feridas tratadas com mel, observou-se somente o crescimento de Pseudomonas aeruginosa. No sétimo dia de tratamento, não se observou crescimento bacteriano nas feridas tratadas com o mel, porém, nas feridas tratadas com o açúcar mascavo e no grupo controle, manteve-se a presença de Pseudomonas aeruginosa.

O Staphylococcus aureus é uma bactéria frequentemente encontradas em feridas cutâneas infectadas, sendo resistente à baixa atividade da água (HADDAD et al., 2000; MORRIS, 2008). Por outro lado, a Pseudomonas aeruginosa é um patogênico oportunista, ou seja, que raramente causa doenças em um sistema imunológico saudável, mas explora eventuais fraquezas do organismo para estabelecer um quadro de infecção. É a causa mais comum de infecções no ouvido e por queimaduras, e é o mais frequente colonizador de equipamentos médicos (HADDAD et al., 2000; HENRIQUES, 2004). De acordo com MATHEWS \& BINNINGTON (2002), o mel e o açúcar mascavo possuem propriedades antibacterianas. Sendo produtos com alta osmolaridade, inibem o crescimento bacteriano, devido à pouca presença de água livre. Quando o mel é diluído pelo exsudado, consequentemente, a sua osmolaridade diminui, mas os seus componentes adicionais como a glicose, frutose, enzimas, o ácido glucónico, minerais e vitaminas, garantem que ele mantenha o seu efeito antibacteriano, ao contrário do açúcar mascavo, que, ao ser diluído pelo exsudado, diminui a sua capacidade osmótica e consequentemente a sua capacidade antibacteriana (HADDAD et al., 2000). $\mathrm{O}$ pH baixo do mel e do açúcar mascavo também contribui para a inibição do crescimento de microrganismos como a E.coli, Proteus mirabilis, Salmonella typhimurium, Staphyllococcus spp., Streptococcus spp., dentre outros (HENRIQUES, 2004; MORRIS, 2008).

Ao sétimo dia de tratamento, nos grupo I, II e III, verificou-se, pela avaliação histopatológica, na região mais superficial das feridas, um infiltrado inflamatório, caraterizado pela presença de neutrófilos, focos hemorrágicos e tecido de granulação. Nas regiões mais profundas das feridas, verificou-se a proliferação do tecido de granulação, com presença de focos hemorrágicos e menor quantidade de neutrófilos (Figura 1A e B).

Ao $14^{\circ}$ dia após a cirurgia, observou-se, nas feridas tratadas com mel, a formação de epitélio, tecido conjuntivo organizado e neovascularização. Nas feridas do grupo tratadas com o açúcar mascavo e do grupo controle, foi possível observar o início da formação do epitélio, tecido de granulação e presença de neutrófilos (Figura 2A e B). No $21^{\circ}$ dia de tratamento, no grupo tratado com o mel foi possível observar epitélio, membrana basal definida e queratinização superficial. $\mathrm{O}$ tecido conjuntivo apresentava-se organizado, com 


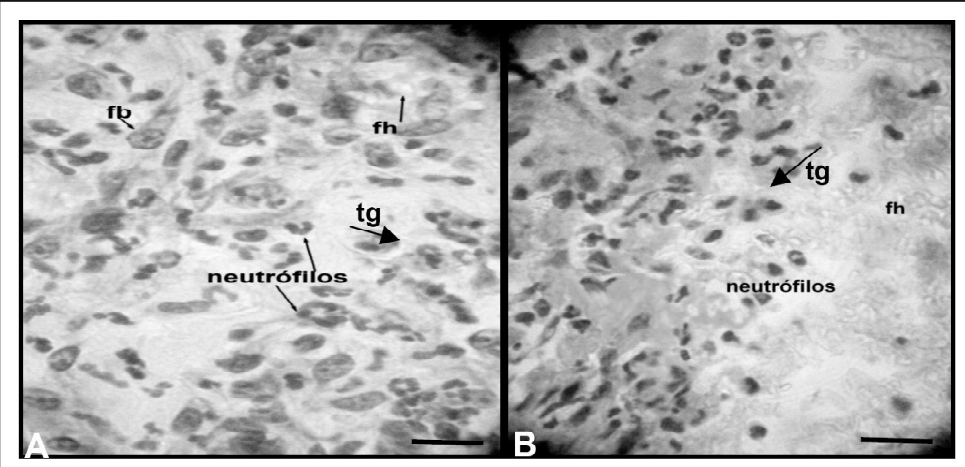

Figura 1 - Fotomicrografia das feridas ao sétimo dia de tratamento com o mel (A) e com o açúcar mascavo (B). Focos hemorrágicos (fh), tecido

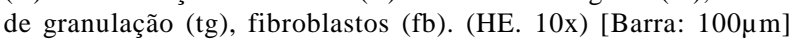
(Arquivo pessoal do autor, 2012).

ausência de inflamação e presença de folículos pilosos, glândulas sebáceas e vasos sanguíneos. Nas feridas do grupo do açúcar mascavo e do grupo controle, observou-se a formação do epitélio (Figura 3A e B).

Histologicamente, ao sétimo dia e $14^{\circ}$ dia de tratamento, verificou-se a presença de reação inflamatória, caracterizada pela presença de elementos celulares, com predominância de neutrófilos em todas as feridas de todos os grupos, com maior ênfase no grupo das feridas tratadas com o açúcar mascavo, seguido do grupo controle e do grupo tratado com o mel. Esses resultados não estão de acordo com o citado pela literatura (SINGER \& CLARK, 1999), que afirmaram que os neutrófilos são as primeiras células encontradas na fase aguda da inflamação, cuja principal ação é a destruição de bactérias, assim como a prevenção de infecções, sendo que, após 24 a 48 horas, degeneramse. A persistência de neutrófilos nas respectivas feridas pode ter sido devido à presença de contaminação, de acordo com os swabs realizados.

\section{CONCLUSÃO}

De acordo com as condições experimentais do estudo, pode-se concluir que o mel cicatriza mais rápido em relação ao açúcar mascavo, tendo um tempo aproximado de cicatrização de 16 dias, dois dias a menos em relação ao açúcar mascavo. O mel promove a cicatrização mais rapidamente ao estimular a formação de tecido de granulação e reepitelização em relação ao açúcar mascavo. Além disso, apresenta maior efeito antibacteriano em relação ao açúcar mascavo.

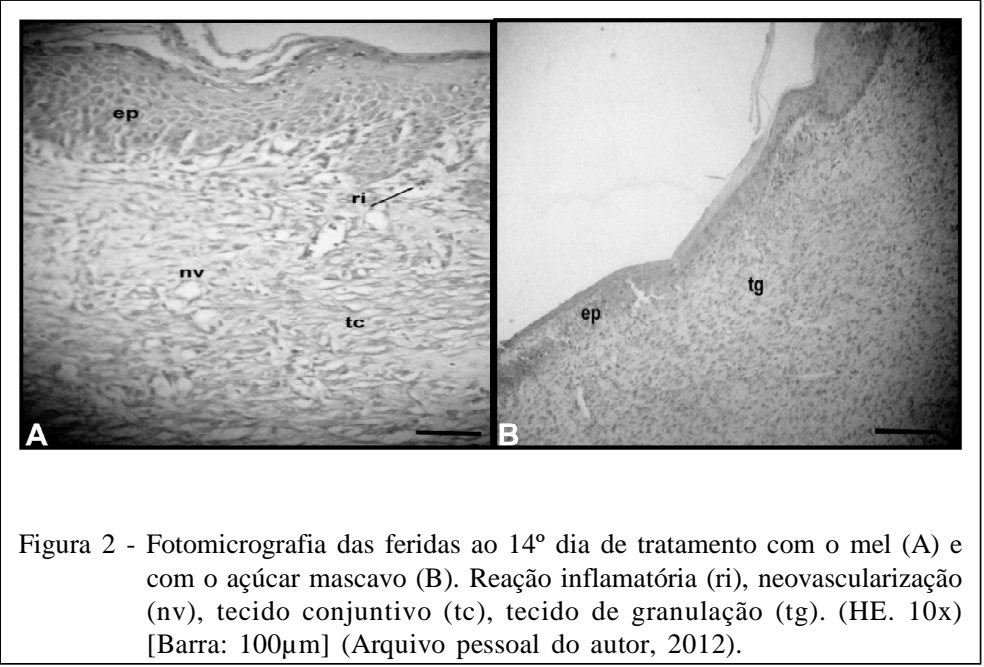

Ciência Rural, v.42, n.12, dez, 2012. 


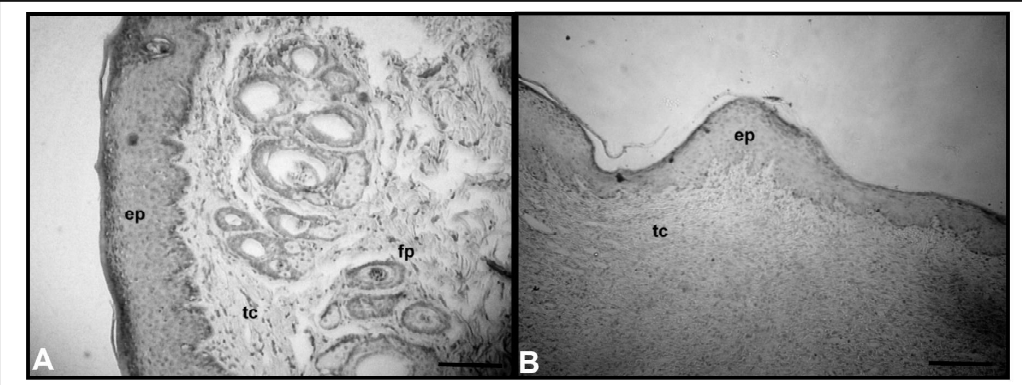

Figura 3 - Fotomicrografia das feridas ao $21^{\circ}$ dia de tratamento com o mel (A) e com o açúcar mascavo (B). Epitélio (ep), tecido conjuntivo (tc), folículo piloso

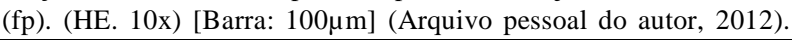

\section{FONTES DE AQUISIÇÃO}

a - Chemivex, Chemitec. São Paulo. Brasil.

b - Rimadyl, Bremer Pharma, Alemanha.

c - Morphine Sulphate-Fresenius PF, Bodene, África do Sul.

d - Ketamina Hydroclroride, Rotex Medica, Alemanha.

e - Domitor, Pfizer laboratories, África do Sul.

f - Isoflurane, Nicholas Piramal, Índia.

g - Antisedan Pfizer laboratories, África do Sul.

\section{COMITÊ DE ÉTICA E BIOSSEGURANÇA}

\author{
Botucatu, SP, Brasil.
}

Protocolo 58/2012-CEUA - FMVZ - UNESP.

\section{REFERÊNCIAS}

AGREN, M.S. et al. A comparative study of three occlusive dressing in the treatment of full-thickness wounds in pigs. $\mathbf{J}$ Am Acad Derm., vol.36, n.1, p. 53-58, 1997. Disponível em: <http://www.jaad.org/article/S0190-9622(97)70325-6/pdf >. Acesso em: 05 jun. 2011. doi: S0190-9622(97)70325-6.

CAVAZANA, W.C. et al. Açúcar (sacarose) e triglicerídeos de cadeia média com ácidos graxos essenciais no tratamento de feridas cutâneas: estudo experimental em ratos. Anais Brasileiros de Dermatologia, vol.84, n.3, p. 229-36, 2009. Disponível em: <http://www.scielo.br/pdf/abd/v84n3/ v84n03a03.pdf >. Acesso em: 09 jun. 2011.

HADDAD, M.C. et al. Influência do açúcar no processo de cicatrização de incisões cirúrgicas infectadas. Rev latinoamericana de enferm, vol.8, n.1, p.57-65, 2000. Disponível em: 〈http://www.scielo.br/pdf/rlae/v8n1/12435>. Acesso em: 19 jun. 2011. doi: 48075_5764.

HENRIQUES, A. Mel: Um milagre da natureza para o tratamento de feridas School of Applied Sciences; University of Wales Institute; Wales, Cardiff, UK, 2004. Disponível em: <http:// www.Forma-te.com/Mediateca>. Acesso em: 09 jun. 2011.

MATHEWS, K.A.; BINNINGTON, A.G. Wound management using honey. Comp Cont Educ Pract Vet, vol.24, n.1, p. 5360, 2002. Disponível em: <http://www.jacksscale.com/ woundmanagementhoney.pdf $>$. Acesso em: 08 jun. 2011.

MOLAN, P.C. The role of honey in the management of wounds. J Wound Care, vol.8, n.8, p.415,2001. Disponível em: <http:/ /researchcommons.waikato.ac.nz/bitstream/handle/10289/ $2041 /$ The $\% 20$ role $\% 20$ of $\% 20$ honey.pdf?sequence $=1>$. Acesso em: 09 jun. 2011. doi:10289/2041.

MORRIS, C. The use of honey in wound care and the Mesitran product range. Wounds UK, vol.4, n.3, p. 84-87, 2008. Disponível em: 〈http://www.wounds-uk.com/pdf/content_9225.pdf〉. Acesso em: 09 jun. 2011.

OLIVEIRA, S.T. et al. Formulações de confrei na cicatrização de feridas cutâneas de ratos. Rev FZVA Uruguaiana, vol.7/8, n.1, p.6474, 2000. Disponível em: <http://revistaseletronicas.pucrs.br/ ojs/index.php/fzva/article/viewFile/2058/1552>. Acesso em: 09 jun. 2011. doi: 2058/1552.

PANTHONG, A. et al. Analgesic, anti-inflammatory and venotonic effects of Cissus quadrangularis. J Ethnopharmacology, vol.1, p.110, 2007. Disponível em: <http://www.sciencedirect.com/science/article/pii/ S0378874106004727>. Acesso em: 09 jun. 2011. doi: S0378874106004727.

PASCHOALINI, M.A. et al. Regulação do peso corporal. In: Seminário de interação sobre os aspectos morfofuncionais orais de clínica médica e de saúde pública. Universidade Federal de Santa Catarina, Brasil, p. 76, 2005.

RAHAL, S.C. et al. Pomada orgânica natural ou solução salina isotônica no tratamento de feridas limpas induzidas em ratos. Ciên Rural, vol.31, n.6, p.1007-1011, 2001. Disponível em: <http://www.scielo.br/pdf/cr/v31n6/a15v31n6.pdf >. Acesso em: 19 jun. 2011.

SANTOS, K.A.; NEVES, R.S. Uso terapêutico do açúcar mascavo em ulcerações. HU Ver, vol.21, p.35-44, 1995. Disponível em: <http://bases.bireme.br/cgibin/wxislind.exe/iah/online/ ?Isis Script $=$ iah $/$ iah . is \& src $=$ google \&b ase $=$ LILACS \& lang $=p \&$ nextAction $=$ lnk\&exprSearch $=221145 \&$ indexSearch $=I D>$. Acesso em: 09 jun. 2011.

SINGER, A.J.; CLARK, R.A. Cutaneous wound healing. N Engl J Med., vol.341, n.10, p. 738-746, 1999. Disponível em: <http:/ /www.nejm.org/doi/full/10.1056/NEJM199909023411006>. Acesso em: 09 jun. 2011. doi: 10.1056/NEJM199909023411006.

YOUNG, T. Honey: rediscovering an ancient healer. Pract Nurs, vol.16, n.11, p. 542-547, 2005. Disponível em: <http:/ /www.internurse.com/cgi-bin/go.pl/library/ article.cgi?uid=19972; article=PN_16_11_542_547; format $=$ pdf $>$. Acesso em: 09 jun. 2011. doi: PN_16_11_542_547. 